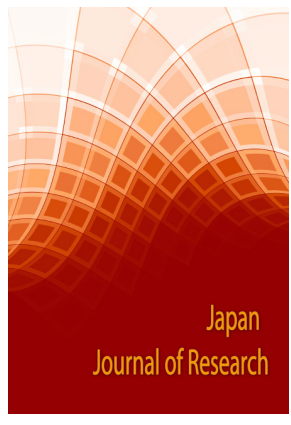

Correspondence

Micheli M

Department of Agricultural, Food and Environmental Sciences, University of Perugia, Borgo XX Giugno 74 - 06121 Perugia, Italy

E-mail: maurizio.micheli@unipg.it

- Received Date: 03 Apr 2020;

- Accepted Date: 25 Apr 2020;

- Publication Date: 30 Apr 2020.

Keywords

Trees, Municipalities, Benefits, Green management, Pruning.

\section{Copyright}

(C) 2020 Science Excel. This is an openaccess article distributed under the terms of the Creative Commons Attribution 4.0 International license.

\title{
Urban Green and Citizens: Complicated Relationship
}

\author{
Micheli $\mathbf{M}^{1}{ }^{*}, \mathbf{D}^{\prime}$ Addato $\mathbf{N}^{1}$ and Gulias Leon $\mathrm{J}^{\mathbf{2}}$ \\ 'Department of Agricultural, Food and Environmental Sciences, University of Perugia, Italy. \\ ${ }^{2}$ Department of Biology, University of the Balearic Islands, Carretera de Valldemossa, Spain.
}

\section{Urban green for urban health}

Cities occupy only $2 \%$ of the world's land surface and are home to more than $70 \%$ of the world population. It is clear that the urban environment is different from the natural one and it results in a reduction of the average life of trees in cities. The spread of the green city is considered one of the main indices of civilization and livability of urban areas.

The relations between plants (trees) and citizens have a role in the development of our society, affecting areas of environmental, social and economic science. In an urban environment, people communicate with Green through formal and informal rules, management strategies and cultivation practices; validity or not of these institutions has an impact on the health of plants and their ability to deliver these benefits in terms of health and quality of life of society. 'Green environments are healthy environments: this is the message repeated again and again from healthcare research that points towards a positive relationship between greenspace and general health [1]. Several studies have provided clear evidence of an essential role in sustainable cities and multiple benefits from urban green, through various mechanisms, and with differential impacts in populations. Views of nature from homes and offices provide restorative experiences that ease mental fatigue and help people concentrate. A series of studies on human stress caused by general urban conditions and city driving show that views of nature reduce the stress response of both body and mind. It has been showed that the access to green space is associated to human health [2].

Trees benefits

Trees represent a great part of plants in urban areas (Figure 1): they increase quality of citizens life by benefiting economy, environment, and health. In particular they: improve the appearance of neighborhoods, resulting in higher home values; clean the air and water by capturing pollutants that lower air and water quality; reduce urban runoff, resulting in lower storm water management costs; decrease the demand for energy and reduce cooling and heating bills; foster healthy communities by creating safe, open spaces; help to protect city pavements and roads; lower the hydrocarbon emissions; reduce the urban heat island effect; improve cognitive functions; promote urban biodiversity; control soil erosion; may reduce crime; sequester carbon dioxide; absorb noises; increase privacy; mitigate climate change; encourage slower driving; improve the attention of drivers; induce consumers preferences; influence occupancy rates.

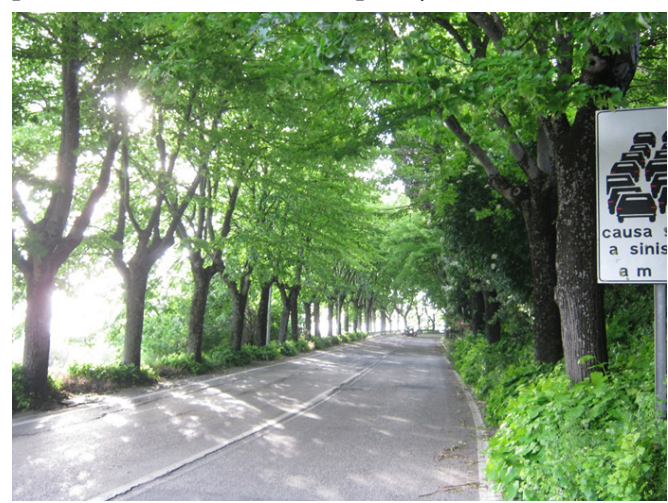

Figure 1. Street trees in Perugia (Italy).

\section{Green care}

As consequence, citizens expect that the public administrators have care of trees in urban areas and more attention needs to be paid to green spaces planning and management. In many Countries the greater part of that job has done by the public authority because normally is more efficient and more professional. In Italy the maintenance of the green areas has carried out only partially by public authority which has been hit hard in recent years by cuts in financial resources [3]. So, the tools of planning and management of urban green, called in Italian "Piano del Verde" and "Regolamento del Verde", have not yet been adopted by all municipalities, therefore, even today, there is necessity to strongly confirm the importance of protecting this common heritage. Both could allow to achieve the functional classification of green areas, which constitutes the first indispensable step for a better use of green areas, as well as the detailed description of their characteristics and agronomic requirements, the pathological emergencies and finally the costs and benefits of technical interventions. Until the benefits are not valued explicitly, they will still be valued implicitly through policy decisions. So, the economic value assessment related to the benefits of each element composing green urban areas is a strategic information able to influence planning choices of the local administration [4], because only the term "public value" describes widely held public perceptions regarding the function and service contributions of any public entity just like in the case of the urban green [5]. 


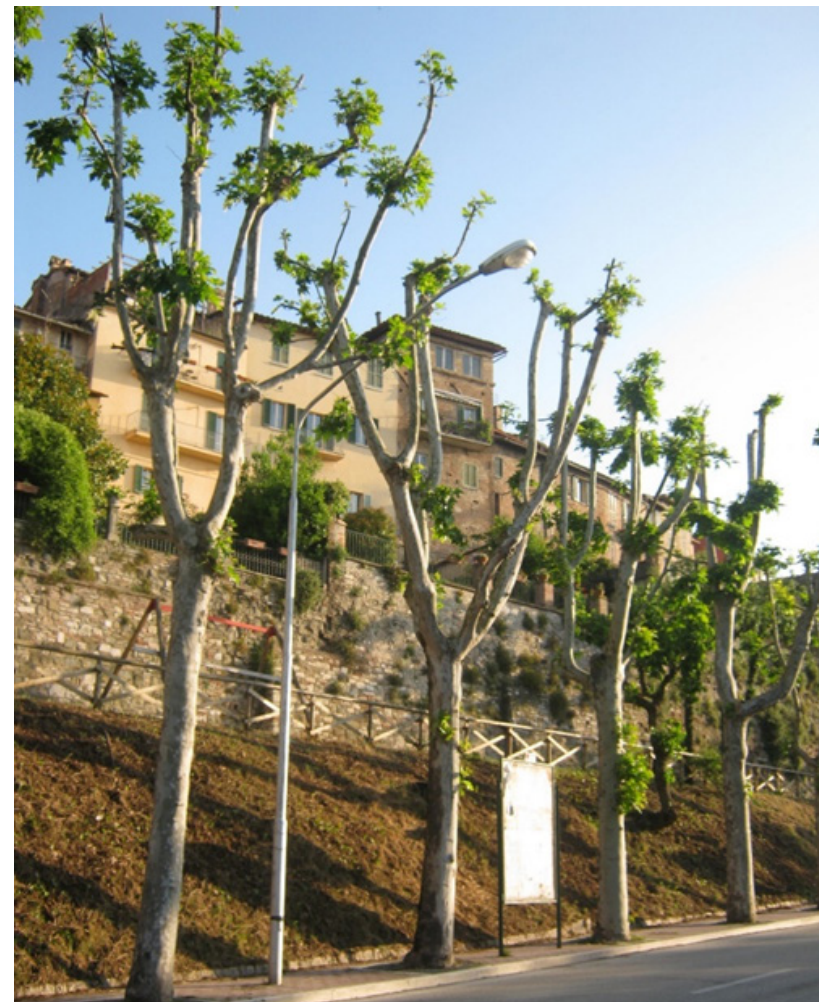

Figure 2. Consequences of topping on trees in urban area.

\section{Conflictual relationship}

But we are so sure that the relationship between humans and plants can be fueled by the best intentions of peaceful coexistence? Unfortunately, usual hostile attitudes seem to be between citizens and plants; it's not uncommon to hear people complaining why trees represent obstacle to the car park, roots damage sidewalks, leaves will dirty streets, not to mention, for those who suffer, allergies caused by pollen during blossom. Another sad aspect is represented by the acts of vandalism towards plants. As reported by Pauleit and coll. [6], vandalism affects up to $30 \%$ of newly planted street trees in some towns and cities in Europe. Moreover, the bad ordinary management practices such as topping during the pruning of urban trees (Figure 2) are common. Topping is the drastic removal or cutting back of large branches in mature trees. The tree is sheared like a hedge and the main branches are cut to stubs. Topping is often referred to as heading, stubbing, or dehorning [7]. Unfortunately, this practice is very common, even though extensive amounts of literature have been written on the subject and why it should not be done. Topping causes many problems. The lack of leaves means the tree cannot produce the nutrients it needs to feed itself. Open wounds can become entry points for many pests and diseases that otherwise may not affect the healthy tree. If the tree does not have enough stored energy reserves to do so, it will be seriously weakened and may die [8].

\section{Help for our trees}

The relations between plants and citizens seem precarious but have an essential role in the development of our society, affecting environmental, social and economic aspects. Would we like to help our communities on protection and expansion of tree resources? So, we all have to cause that the choices of the public authority are focused on: inventory of public forest property; assessment of the current status of trees; training on correct techniques of trees management with the aim to entrust the plants care to capable arborists; identification of objectives and prioritization of needs; periodic and strict monitoring of urban forests.

Will we be able to achieve these priorities? It affects our very survival. Take or leave: there are no alternatives.

\section{References}

1. Shackell A, Walter R. Greenspace design for health and well-being. Forestry Commission 231 Corstorphine Road, Edinburgh. 2012.

2. McPherson EG. Simpsona JR, Xiao Q, et al. Million trees Los Angeles canopy cover and benefit assessment. Landscape and Urban Planning. 2011;99: 40-50.

3. Marone E, Fratini R. Evaluation of efficiency of public spending for management of green urban areas. Proceedings of Urban Forestry Bridges 2006 (May 22-26, Florence, Italy): 37-38.

4. Riccioli F, Scozzafava G. Evaluation of green urban areas: some study cases in Florence. Proceedings of Urban Forestry Bridges 2006 (May 22-26, Florence, Italy): 33-34.

5. Wolf KL. Economics and public value of urban forests. Urban Agriculture Magazine, Special Issue on Urban and Periurban Forestry. 2004;13:31-33.

6. Pauleit S, Jones N, Garcia-Martin G, Garcia-Valdecantos JL, Rivière LM, Vidal-Beaudet L. Tree establishment practice in towns and cities - Results from a European survey. Urban Forestry \& Urban Green. 2002;1:83-96.

7. McKenzie R. What's wrong with topping trees? Frequently Asked Question Series FNR-FAQ-14-W, Purdue University Cooperative Extension Service, West Lafayette, IN. 2000.

8. Carden K. Tree topping and why you shouldn't do it. Pruning Bulletin, Harpers Ferry Tree Committee, Harpers Ferry, West Virginia. 2009. 